\title{
Physical inactivity and idiopathic pulmonary embolism in women: prospective study
}

\author{
Christopher Kabrhel attending physician assistant professor of surgery ${ }^{12}$, Raphaëlle Varraso \\ researcher/epidemiologist ${ }^{34}$, Samuel Z Goldhaber attending physician professor of medicine ${ }^{52}$, Eric \\ Rimm associate professor ${ }^{67}$, Carlos A Camargo Jr attending physician associate professor ${ }^{17}$
}

${ }^{1}$ Department of Emergency Medicine, Massachusetts General Hospital, MA, USA; ${ }^{2}$ Harvard Medical School, Boston, MA; ${ }^{3}$ INSERM, CESP Centre for Research in Epidemiology and Population Health, U1018, Respiratory and Environmental Epidemiology Team, F-94807, Villejuif, France; ${ }^{4}$ Université Paris Sud 11, UMRS 1018, F-94807, Villejuif; ${ }^{5}$ Department of Medicine, Cardiovascular Division, Brigham and Women's Hospital, Harvard Medical School, Boston, MA; ${ }^{6}$ Departments of Epidemiology and Nutrition, Harvard School of Public Health, Boston, MA ; ${ }^{7}$ Channing Laboratory, Department of Medicine, Brigham and Women's Hospital, Harvard Medical School, Boston, MA

\begin{abstract}
Objectives To determine the association between physical inactivity (that is, a sedentary lifestyle) and incident idiopathic pulmonary embolism.

Design Prospective cohort study.

Setting Nurses' Health Study.

Participants 69950 female nurses who completed biennial questionnaires from 1990 to 2008.

Main outcome measures The primary outcome was idiopathic pulmonary embolism confirmed in medical records. Multivariable Cox proportional hazards models controlled for age, body mass index (BMI), energy intake, smoking, pack years, race, spouse's educational attainment, parity, menopause, non-aspirin non-steroidal anti-inflammatory drugs, warfarin, multivitamin supplements, hypertension, coronary heart disease, rheumatological disease, and dietary patterns. The primary exposure was physical inactivity, measured in hours of sitting each day. The secondary exposure was physical activity, measured in metabolic equivalents a day.

Results Over the 18 year study period, there were 268 cases of incident idiopathic pulmonary embolism. There was an association between time of sitting and risk of idiopathic pulmonary embolism (41/104 $720 \mathrm{v} 16 / 14$ 565 cases in most inactive $v$ least inactive in combined data; $P<0.001$ for trend). The risk of pulmonary embolism was more than twofold in women who spent the most time sitting compared with those who spent the least time sitting (multivariable hazard ratio $2.34,95 \%$ confidence interval 1.30 to 4.20 ). There was no association between physical activity and pulmonary embolism ( $\mathrm{P}=0.53$ for trend).
\end{abstract}

Conclusions Physical inactivity is associated with incident pulmonary embolism in women. Interventions that decrease time sitting could lower the risk of pulmonary embolism.

\section{Introduction}

Pulmonary embolism is a common cause of cardiovascular morbidity and mortality. The annual incidence in the United States is 1-2 per 1000 adults, similar to that of stroke and myocardial infarction. ${ }^{1-3}$ Pulmonary embolism is typically a consequence of a deep vein thrombosis in the lower extremities. Risk factors for deep vein thrombosis/pulmonary embolism include age, limb immobilisation, malignancy, pregnancy, surgery, and acquired or inherited thrombophilias. Arterial and venous thrombosis share multiple risk factors such as obesity, cigarette smoking, and hypertension. ${ }^{4-7}$

Associations between physical inactivity, physical activity, and pulmonary embolism remain uncertain. Some published case-control studies found that exercising on a regular basis decreases the risk of venous thrombosis by $30-50 \%$ compared with not exercising. ${ }^{8}{ }^{80}$ Other studies, however, including prospective cohort studies, have found that physical activity is associated with an increased risk of venous thromboembolism. ${ }^{5-13}$ This inconsistency could reflect the difference between short term exercise, which might increase the risk of thrombosis by increasing inflammation and injuries to extremities, and regular exercise, which might decrease the risk of thrombosis by improving blood flow. It is also likely that overall physical activity does not fully describe an individual's lifestyle. For example, the same number of metabolic equivalents a week can be achieved by maintaining a relatively high level of baseline activity (such as walking for eight hours) without ever engaging in strenuous physical activity, or by spending most of the time sedentary but engaging in brief periods of strenuous physical activity (such watching television for seven hours and then running for one hour). Therefore, it is just as important to assess physical inactivity (a sedentary lifestyle) as it is to assess physical activity (exercise). 
To better define the association between physical inactivity and risk of pulmonary embolism, we performed a prospective observational cohort study in 69950 women who provided detailed information about their lifestyle habits on biennial questionnaires. We hypothesised that physical inactivity, defined by more time spent sitting, is associated with an increased incidence of pulmonary embolism.

\section{Methods}

\section{Participants}

The Nurses' Health Study (www.channing.harvard.edu/nhs) is a longitudinal cohort study established in 1976. At baseline, questionnaires were sent to registered nurses living in one of 11 populous states in the United States. The state boards of nursing and the American Nurses' Association provided this information. After exclusions on the basis of age, sex, and incomplete questionnaire information, a cohort of 121700 women aged 30-55 (in 1976) was established. Though there were no exclusions by race, about $98 \%$ of the cohort is white, corresponding to the race of women entering nursing in 1976.

Every two years, participants are mailed a questionnaire assessing risk factors and the interval occurrence of disease. Records of diagnoses of pulmonary embolism have been collected prospectively on each biennial questionnaire since study inception. Data describing time sitting were collected in 1988 and 1990, and data describing physical activity have been collected since 1980 . We therefore began prospective follow-up in 1990 among women who responded to both the 1988 and 1990 questionnaires ( $n=99$ 290). Outcome ascertainment occurred from 1990 to 2008.

Participants in the Nurses' Health Study initially receive a long questionnaire, which includes questions about physical inactivity. Participants who do not respond to the long questionnaire receive a short questionnaire, which focuses on occurrence of disease but does not include questions about physical inactivity. We excluded 28235 women from the analysis because they did not report their time sitting (either because they did not complete the long questionnaire in either 1998 or 1990 or because of missing values). No missing data were imputed. We also excluded 1105 women because pulmonary embolism occurred before 1990 . Our present analysis included 69950 women.

\section{Exposures}

The primary exposure was physical inactivity, defined a priori by the number of hours spent sitting a day. Time sitting was assessed in 1988 when women were asked to report "the number of hours per week [they] spent sitting (e.g., at work, at home, driving)" as none, 1, 2-5, 6-10, 11-20, 21-40, 41-60, 61-90, or over 90. It was assessed again in 1990 when women were asked to report "the number of hours per week [they] spent sitting at home" as less than half an hour, half to 1 hour, 1-2, 3-5, 6-10, 11-20, 21-40, 41-60, 61-90, or over 90. In 1990, the questionnaire also included questions assessing time sitting in the car or at work and time spent watching television. We focused on time sitting at home, as this accounted for most of the time sitting during the day, and we thought it was most likely to reflect the overall time sitting as assessed in 1988. For each questionnaire response, we categorised and assigned point scores to time sitting in hours/week: low $(<10)=1$ point, medium $(11-40)=2$ points, and high $(>40)=3$ points. We then added each woman's point score for time sitting in 1988 and 1990 to define each her overall time sitting. Thus, each woman was assigned to one of five categories of time sitting, with point values ranging from 2 (low time sitting in 1988 and 1990) to 6 (high time sitting in 1988 and 1990).

In a secondary analysis, we assessed the association between overall physical activity, as measured in metabolic equivalents a week, and incident pulmonary embolism. Data related to physical activity have been collected with a physical activity questionnaire since 1980 but for consistency with the physical inactivity analysis, we limited this to data collected in 1988. On the physical activity questionnaire, participants were asked to report the average number of hours a week they spent on various physical activities and sports. They were also asked to report the average number of flights of stairs they climbed each week and an estimate of their usual walking pace. We combined these data to determine each participant's overall metabolic equivalents a week. Previous studies have validated the use of the physical activity questionnaire and shown it to be correlated with physical activity diaries. ${ }^{14}{ }^{15}$ For the purpose of analyses, we divided physical activity into fifths (physical activity in 1988).

\section{Outcomes}

On each questionnaire, nurses were asked whether they had received a physician's diagnosis of pulmonary embolism. Those reporting pulmonary embolism, but without a history of malignancy, received a follow-up letter requesting medical records from the facility where the pulmonary embolism was diagnosed. We reviewed these records in detail and coded cases. Incident cases for which the medical record included imaging diagnostic of pulmonary embolism were considered as confirmed. Imaging was considered as diagnostic if the radiologist reading the study noted either a ventilation or perfusion lung scan with a high probability for pulmonary embolism, a filling defect on contrast enhanced computed tomography of the pulmonary vasculature, or a filling defect on catheter based pulmonary angiography. Women who did not return a questionnaire contributed person years to follow-up if they returned a questionnaire during a subsequent cycle. Those reporting pulmonary embolism had the date of diagnosis confirmed on review of medical records, with the date of confirmatory chest imaging used as the date of diagnosis. Confirmed cases were coded as "idiopathic pulmonary embolism" when review of medical records showed no history of surgery or major trauma within one month of the diagnosis of pulmonary embolism and no history of active malignancy. One month is a typical timeframe used in studies assessing the probability of pulmonary embolism after trauma or surgery. ${ }^{16} 17$ If the woman died before imaging but autopsy records confirmed the cause of death was pulmonary embolism, we considered this as a confirmed pulmonary embolism. These cases were also considered idiopathic unless available medical records showed an association with recent surgery, trauma, or malignancy. Using this definition, over 18 years of follow-up, we identified 268 cases of incident idiopathic pulmonary embolism.

\section{Subgroup analyses}

We investigated the acute effect of physical activity by separately analysing the association between physical inactivity and pulmonary embolism among nurses at or above the median level of physical activity (metabolic equivalents/day) and among nurses below the median level. As physical inactivity can increase with age, we also stratified our analysis according to age $(<65$ and $\geq 65){ }^{18}{ }^{19}$ In a third and final subgroup analysis, we stratified according to obesity, which also tends to be associated with physical inactivity, with strata for women with 
BMI $<30.0$ and $\geq 30 .{ }^{19}$ To preserve statistical power in each of the subanalyses, we combined time sitting into three groups (lowest (physical inactivity score 2), medium (score 3 or 4), and highest (score 5 or 6 )), rather than the five used in the primary analysis.

\section{Confounders}

When possible, covariates were obtained from the 1990 questionnaire and updated every two years. Variables included age, BMI, total energy intake, coronary heart disease, hypertension, menopausal status, multivitamin use, non-aspirin non-steroidal anti-inflammatory drugs, parity, race, rheumatological disease, spouse's highest educational attainment, smoking status, pack years of smoking, warfarin use (first obtained in 1994), and dietary intake/pattern. Previous studies have validated the use of these self reported measurements. ${ }^{20-22}$ BMI was updated biennially and calculated according to the standard formula (weight $(\mathrm{kg}) /$ height $\left.(\mathrm{m})^{2}\right)$. Total energy intake was measured in kilocalories a day. Coronary heart disease was defined as any history of angina, coronary artery stenosis, or myocardial infarction and was considered dichotomous. Hypertension, use of drugs and vitamins, and rheumatological disease (any history of systemic lupus erythematosus or rheumatoid arthritis) were also considered dichotomous.

Menopausal status was categorised as premenopausal or postmenopausal and according to whether oestrogen or progesterone replacement (oral or patch) had been or was being used. Parity was categorised as nulliparous, one, two to three, or four or more children. Race and spouse's highest educational attainment were obtained from the 1992 questionnaire. As most (90\%) of Nurses' Health Study participants are white, reflecting the demographics of the nursing profession in 1976, we categorised race as white or non-white.

In this cohort of female nurses, who share a profession and therefore relatively similar education, we used spouse's highest educational attainment (high school, college, or graduate school) as a proxy for socioeconomic status. Smoking was categorised as never, ex-smoker, or current smoker. Pack years of smoking were calculated among ever smokers. Dietary pattern was defined as a prudent pattern (emphasising intake of fruit, vegetables, fish, and wholegrain products) or a western pattern (emphasising intake of refined grains, cured and red meats, desserts, and chips (French fries). ${ }^{23}$ We performed our primary analysis including all of these factors in our multivariable model. In addition, to address the likelihood that physical inactivity is related to BMI, total energy intake, dietary patterns and physical activity, we analysed a second model with these covariates removed.

\section{Statistical analysis}

We performed age and multivariable adjusted Cox proportional hazards analysis to obtain hazard ratios and $95 \%$ confidence intervals for the risk of pulmonary embolism with physical inactivity (time sitting a day). To control as finely as possible for confounding by age, calendar time, and any possible two way interactions between these two time scales, we stratified the analysis jointly by age in months at the start of follow-up and calendar year of the current questionnaire cycle. For all analyses of physical inactivity, we used the group with the lowest amount of time sitting as the reference group. For the analyses of physical activity, we used women in the lowest fifth of physical activity as the reference group. We tested for trend across the categories of physical inactivity by treating the categories as an ordinal variable in a proportional hazards model. We formally tested for interaction. All analyses used SAS version 9.1 (SAS Institute, Cary, NC).

\section{Results}

There were $268(0.4 \%)$ cases of incident idiopathic pulmonary embolism among the 69950 women in our primary analysis of physical inactivity. Incident pulmonary embolism was diagnosed in the following years of the questionnaire cycle: 1990-2 $(n=15$, $6 \%), 1992-4(\mathrm{n}=19,7 \%), 1994-6(\mathrm{n}=30,11 \%), 1996-8(\mathrm{n}=37$, $14 \%), 1998-2000(n=29,11 \%), 2000-2(n=41,15 \%), 2002-4$ $(\mathrm{n}=43,16 \%), 2004-6(\mathrm{n}=52,19 \%)$, and 2006-8 $(\mathrm{n}=2,1 \%)$. There were $267(0.4 \%)$ cases of incident idiopathic pulmonary embolism among the 69647 women in our secondary analysis of physical activity. Table 1 shows baseline characteristics of women in the primary analysis, adjusted for age and stratified according to inactivity time. In 1988, 20475 (29\%) women sat $<10$ hours a week, $34331(49 \%)$ sat between 11 and 40 hours a week, and 15144 (22\%) sat 41 or more hours a week. In 1990, when the question focused on sitting at home, 29875 (43\%) of women sat $<10$ hours a week, $36428(52 \%)$ sat between 11 and 40 hours a week, and 3647 (5\%) sat 41 or more hours a week. The distribution of time sitting in 1988 was more similar to time sitting at home in 1990 than time sitting at work, with most nurses $(43530,64 \%)$ reporting $<10$ hours a week sitting at work in 1990. Most women were white and had given birth to at least two children. There were no major differences in the baseline characteristics across categories of inactivity, though women with more physical inactivity tended to have a higher energy intake, higher BMI, and a lower level of physical activity.

After adjustments for age, coronary heart disease, hypertension, menopausal status, multivitamin use, non-aspirin non-steroidal anti-inflammatory drug use, parity, race, rheumatological disease, spouse's highest educational attainment, smoking status and pack years of smoking, and warfarin use, physical inactivity was associated with an increase in the risk of idiopathic pulmonary embolism (hazard ratio for a 1 unit increased score $1.29,95 \%$ confidence interval 1.15 to $1.45 ; \mathrm{P}<0.001$ ) (table 2 ). For women with the most physical inactivity, the risk of pulmonary embolism was more than twice that of women with the least physical inactivity (multivariable hazard ratio 2.68, 1.50 to 4.79 ). Further adjustments for BMI, total energy intake, physical activity, and dietary pattern led to similar results. Subanalysis excluding women taking warfarin also yielded similar results (data not shown).

We did not find a significant association between increased overall physical activity (metabolic equivalents a week) and incident idiopathic pulmonary embolism. Across fifths of physical activity, the multivariable hazard ratios were 1.00 (reference), 0.91 (0.62 to 1.33), 1.17 (0.82 to 1.67$), 0.85$ (0.58 to 1.26$)$, and 0.89 ( 0.60 to 1.32$)(\mathrm{P}=0.53$ for trend). Further adjustment for physical inactivity led to similar result $(\mathrm{P}=0.42$ for trend).

\section{Subanalyses}

We performed several subanalyses of the association between physical inactivity and pulmonary embolism. To assess the effect of brief periods of physical activity, we stratified our analysis of physical inactivity according to overall level of physical activity (table 3 ). Women below the cohort median of 8.4 metabolic equivalents of physical activity a week had a significantly increased risk of idiopathic pulmonary embolism with time sitting (multivariable hazard ratio $1.30,1.00$ to 1.69 ; $\mathrm{P}=0.05$ for trend), whereas this association was not significant 
among women at or above the cohort median of physical activity (1.25, 0.89 to $1.76 ; \mathrm{P}=0.20$ for trend). The formal test for interaction was not significant ( $\mathrm{P}=0.59$ for interaction).

We stratified our analysis according to age $(<65$ and $\geq 65)$. We found a similarly strong association between physical inactivity and risk of pulmonary embolism in both groups (multivariable hazard ratio 1.54 ( 1.11 to $2.12 ; \mathrm{P}=0.009$ for trend) and 1.32 ( 0.99 to $1.75 ; \mathrm{P}=0.06$ for trend), respectively; $\mathrm{P}=0.65$ for interaction).

Lastly, to assess whether the association between physical inactivity and pulmonary embolism varied with obesity, we stratified our analysis according to BMI. We reported a significant positive association between physical inactivity and pulmonary embolism for women with BMI <30: the risk of pulmonary embolism by time sitting was 1.39 ( 0.86 to 2.25$)$ and 2.33 (1.37 to 3.99) for medium and high levels of inactivity (multivariable hazard ratio $1.42,1.23$ to $1.66 ; \mathrm{P}<0.001$ for trend). For women with BMI $\geq 30.0$, the association was not significant; the risk for pulmonary embolism was $0.69(0.41$ to 1.17$)$ and 0.97 (0.53 to 1.77), for similar categories (multivariable hazard ratio $1.01,0.84$ to $1.23 ; \mathrm{P}=0.90$ for trend). The formal test for interaction was not significant ( $\mathrm{P}=0.22$ for interaction).

\section{Discussion}

In this large cohort of female nurses, we found an association between physical inactivity (time sitting) and risk of idiopathic pulmonary embolism. Women with the most physical inactivity had more than twice the risk of pulmonary embolism compared with those with the least physical inactivity. The association was strongest among women who also reported minimal regular physical activity. The strength of this association is similar to that of several other recognised risk factors for pulmonary embolism, such as use of oestrogen, obesity, and smoking. ${ }^{4-28}$

\section{Comparison with other studies}

This prospective cohort study showed that physical inactivity is associated with an increased risk of pulmonary embolism. The large cohort enabled us to establish a temporally correct relation between physical inactivity and pulmonary embolism and to control for many potential confounders.

Previous epidemiological data on the relation between physical activity (exercise) and pulmonary embolism are inconsistent, with studies reporting both increased and decreased risk. ${ }^{5-12}$ In our analysis we found no significant association between physical activity (metabolic equivalents/week) and the risk of idiopathic pulmonary embolism. In addition, the increased risk of pulmonary embolism associated with physical inactivity was more apparent in women with lower levels of physical activity. This finding suggests that regular physical activity could protect against pulmonary embolism, and periods of physical activity might counteract the effect of physical inactivity. These findings could also help to explain why previous studies of physical activity yielded conflicting results. This warrants further exploration.

\section{Strengths and limitations of the study}

A limitation of our study involves the nature of the cohort: female nurses, $>95 \%$ of whom are white. This represents the demographics of nurses in 1976 but limits the generalisability of our results to other racial/ethnic groups and to men. Our results should be verified in other populations. Moreover, the mean age of our cohort was $>55$ at inception, so our results might not be relevant in younger women. In older people, however, who for various reasons tend be more physically inactive, the association between physical inactivity and pulmonary embolism could be particularly important. ${ }^{29}$ Though follow-up for this study began after the Nurses' Health Study cohort was well established, we recognise that in the early phases of any long term study, participants tend to be healthier than non-participants. Women enrolled in the Nurses' Health Study are different from the general population. Their education, access to medical care, and above average standard of living all might limit generalisability. Nonetheless, there is little biological basis for suspecting that the relation we observed between physical inactivity and pulmonary embolism would differ in other groups of women. Furthermore, the group's relative homogeneity and good baseline health help to minimise confounding by socioeconomic factors, access to healthcare, and health literacy.

We used self reported time sitting as a proxy measure for physical inactivity. We believe that this measure accurately reflects an individual's overall physical inactivity, though we acknowledge that any single measure will not fully describe a person's lifestyle. We used two time points (1988 and 1990) to measure physical inactivity. Though it is possible that levels of physical inactivity changed over time, we did not have the ability to detect any changes. Further studies incorporating direct and continuous measurements of physical inactivity would be beneficial. We also acknowledge that the variable we used to determine the time sitting was different in 1988 and 1990. In 1990, the Nurses' Health Study questionnaire divided time sitting into several categories. We chose time sitting at home to account for the majority of time spent sitting during the day and therefore best reflect a "sedentary lifestyle." Our results, however, could have been slightly different if overall time sitting had been available for analysis in both years. Our case definition for pulmonary embolism was relatively stringent and required confirmation in medical records. As a result, we might have missed some cases. The incidence we found, however, is similar to that previously reported in the literature. Data on one potential confounder, warfarin use, were first collected four years after cohort inception and thus might have been incompletely controlled for in our model. Finally, we consider that our results could have been influenced by measurement bias, investigation bias, or inaccuracies arising from self reported measures of physical inactivity. The observed association between physical inactivity and pulmonary embolism, however, was consistent across subgroups.

\section{Biological mechanisms and public health implications}

It is biologically plausible that physical inactivity could increase the risk of pulmonary embolism. Muscular activity in the lower extremities is required to promote venous blood return. ${ }^{30-32}$ Thus, lack of such activity could result in venous stasis and thrombosis. Lower levels of circulating factors such as tissue plasminogen activator, platelets, and fibrinogen could also play a role by increasing thrombotic tendency and plasma viscosity. ${ }^{33-39}$ Regardless of the pathophysiological mechanism, the public health implications of our findings are potentially profound. Americans lead an increasingly inactive lifestyle, and this could partly explain the high prevalence of pulmonary embolism. ${ }^{40}$ Public health campaigns that discourage physical inactivity among the general population could reduce the incidence of pulmonary embolism.

The Nurses' Health Study is coordinated at the Channing Laboratory, Brigham and Women's Hospital, Boston, MA. We acknowledge the 


\section{What is already known on this topic}

Pulmonary embolism is associated with considerable morbidity and mortality

While studies have explored the association between physical activity (exercise) and pulmonary embolism, few data are available describing the association with physical inactivity (sedentary lifestyle)

\section{What this study adds}

Physical inactivity is associated with increased risk of pulmonary embolism in women

The risk of pulmonary embolism is more than twofold in women who spent the most time sitting compared with those who spent the least time sitting

dedication and hard work of all of the Nurses' Health Study staff, especially Gary Chase, Karen Corsano, Betsy Frost-Hawes, Barbara Egan, and of course the nurses themselves.

Contributors: CK conceived the study, obtained funding, collected the data, planned the analysis, drafted and critically revised the manuscript, and approved the final version for publication. RV and CAC conceived the study, obtained funding, planned and performed the statistical analysis, critically revised the manuscript, and approved the final version for publication. SZG and ER conceived the study, obtained funding, critically revised the manuscript, and approved the final version for publication. CK, RV, and CAC are guarantors.

Funding: This study was funded by the National Institute on Aging, National Institutes of Health, Bethesda, MD (R21AG031079, P01CA87969, and R01HL034594). The funding source had no role in design or conduct of the study; collection, management, analysis, or interpretation of the data; preparation, review, or approval of the manuscript.

Competing interest: All authors have completed the ICMJE uniform disclosure form at www.icmje.org/coi_disclosure.pdf (available on request from the corresponding author) and declare: no support from any organisation for the submitted work; no financial relationships with any organisations that might have an interest in the submitted work in the previous three years; no other relationships or activities that could appear to have influenced the submitted work.

Ethical approval: This study was approved by the human research committee of Partners HealthCare.

Data sharing: Requests for access to data, statistical code, questionnaires, and technical processes may be made by contacting the corresponding author at ckabrhel@partners.org.

1 Silverstein MD, Heit JA, Mohr DN, Petterson TM, O'Fallon WM, Melton LJ 3rd. Trends in the incidence of deep vein thrombosis and pulmonary embolism: a 25-year population-based study. Arch Intern Med 1998;158:585-93.

2 Goldhaber SZ, Visani L, De Rosa M. Acute pulmonary embolism: clinical outcomes in the International Cooperative Pulmonary Embolism Registry (ICOPER). Lancet 1999;353:1386-9.

3 Kurkciyan I, Meron G, Sterz F, Janata K, Domanovits H, Holzer M, et al. Pulmonary embolism as a cause of cardiac arrest: presentation and outcome. Arch Intern Med 2000;160:1529-35.

4 Kabrhel C, Varraso R, Goldhaber SZ, Rimm EB, Camargo CA. Prospective study of BMI and the risk of pulmonary embolism in women. Obesity (Silver Spring) 2009;17:2040-6.

5 Glynn RJ, Rosner B. Comparison of risk factors for the competing risks of coronary heart disease, stroke, and venous thromboembolism. Am J Epidemiol 2005;162:975-82.

6 Goldhaber SZ, Grodstein F, Stampfer MJ, Manson JE, Colditz GA, Speizer FE, et al. A prospective study of risk factors for pulmonary embolism in women. JAMA 1997;277:642-5. Everett BM, Glynn RJ, Buring JE, Ridker PM. Lipid biomarkers, hormone therapy and the risk of venous thromboembolism in women. J Thromb Haemost 2009;7:588-96.

8 Van Stralen KJ, Le Cessie S, Rosendaal FR, Doggen CJ. Regular sports activities decrease the risk of venous thrombosis. J Thromb Haemost 2007;5:2186-92.

9 Van Stralen KJ, Rosendaal FR, Doggen CJ. Minor injuries as a risk factor for venous thrombosis. Arch Intern Med 2008;168:21-6.

10 Cushman M, Kuller LH, Prentice R, Rodabough RJ, Psaty BM, Stafford RS, et al. Estrogen plus progestin and risk of venous thrombosis. JAMA 2004;292:1573-80.

11 Van Stralen KJ, Blom JW, Doggen CJ, Rosendaal FR. Strenuous sport activities involving the upper extremities increase the risk of venous thrombosis of the arm. J Thromb Haemost 2005;3:2110-1.

12 Tsai AW, Cushman M, Rosamond WD, Heckbert SR, Polak JF, Folsom AR. Cardiovascular risk factors and venous thromboembolism incidence: the longitudinal investigation of thromboembolism etiology. Arch Intern Med 2002;162:1182-9.
13 Van Stralen KJ, Doggen CJ, Lumley T, Cushman M, Folsom AR, Psaty BM, et al. The relationship between exercise and risk of venous thrombosis in elderly people. $J$ Am Geriatr Soc 2008;56:517-22.

14 Wilson PW, Paffenbarger RS Jr, Morris JN, Havlik RJ. Assessment methods for physical activity and physical fitness in population studies: report of a NHLBI workshop. Am Heart J 1986;111:1177-92.

15 Wolf AM, Hunter DJ, Colditz GA, Manson JE, Stampfer MJ, Corsano KA, et al. Reproducibility and validity of a self-administered physical activity questionnaire. Int $J$ Epidemiol 1994;23:991-9.

16 Kline JA, Mitchell AM, Kabrhel C, Richman PB, Courtney DM. Clinical criteria to prevent unnecessary diagnostic testing in emergency department patients with suspected pulmonary embolism. J Thromb Haemost 2004;2:1247-55.

17 Wells PS, Anderson DR, Rodger M, Ginsberg JS, Kearon C, Gent M, et al. Derivation of a simple clinical model to categorize patients probability of pulmonary embolism: increasing the models utility with the SimpliRED D-dimer. Thromb Haemost 2000;83:416-20.

18 Bassett DR Jr, Wyatt HR, Thompson H, Peters JC, Hill JO. Pedometer-measured physical activity and health behaviors in US adults. Med Sci Sports Exerc 2010;42:1819-25.

19 Jackson AS, Sui X, Hebert JR, Church TS, Blair SN. Role of lifestyle and aging on the longitudinal change in cardiorespiratory fitness. Arch Intern Med 2009;169:1781-7.

20 Rimm EB, Stampfer MJ, Colditz GA, Chute CG, Litin LB, Willett WC. Validity of self-reported waist and hip circumferences in men and women. Epidemiology 1990;1:466-73.

21 Willett W, Stampfer MJ, Bain C, Lipnick R, Speizer FE, Rosner B, et al. Cigarette smoking, relative weight, and menopause. Am J Epidemiol 1983;117:651-8.

22 Troy LM, Hunter DJ, Manson JE, Colditz GA, Stampfer MJ, Willett WC. The validity of recalled weight among younger women. Int J Obes Relat Metab Disord 1995;19:570-2.

23 Varraso R, Fung TT, Barr RG, Hu FB, Willett W, Camargo CA Jr. Prospective study of dietary patterns and chronic obstructive pulmonary disease among US women. Am J Clin Nutr 2007;86:488-95

24 Goldhaber SZ, Savage DD, Garrison RJ, Castelli WP, Kannel WB, McNamara PM, et al. Risk factors for pulmonary embolism. The Framingham Study. Am J Med 1983;74:1023-8.

25 Heit JA. Risk factors for venous thromboembolism. Clin Chest Med 2003;24:1-12.

26 Heit JA. Venous thromboembolism: disease burden, outcomes and risk factors. J Thromb Haemost 2005;3:1611-7.

27 Heit JA, Silverstein MD, Mohr DN, Petterson TM, O'Fallon WM, Melton LJ 3rd. Risk factors for deep vein thrombosis and pulmonary embolism: a population-based case-control study. Arch Intern Med 2000;160:809-15.

28 Kucher N, Tapson VF, Goldhaber SZ. Risk factors associated with symptomatic pulmonary embolism in a large cohort of deep vein thrombosis patients. Thromb Haemost 2005;93:494-8.

29 Arterburn DE, Crane PK, Sullivan SD. The coming epidemic of obesity in elderly Americans. $J$ Am Geriatr Soc 2004:52:1907-12.

30 Hitos K, Cannon M, Cannon S, Garth S, Fletcher JP. Effect of leg exercises on popliteal venous blood flow during prolonged immobility of seated subjects: implications for prevention of travel-related deep vein thrombosis. J Thromb Haemost 2007;5:1890-5.

31 Sochart $\mathrm{DH}$, Hardinge $\mathrm{K}$. The relationship of foot and ankle movements to venous return in the lower limb. J Bone Joint Surg Br 1999;81:700-4.

32 McNally MA, Cooke EA, Mollan RA. The effect of active movement of the foot on venous blood flow after total hip replacement. J Bone Joint Surg Am 1997;79:1198-201.

33 Folsom AR, Wu KK, Davis CE, Conlan MG, Sorlie PD, Szklo M. Population correlates of plasma fibrinogen and factor VII, putative cardiovascular risk factors. Atherosclerosis 1991;:91:191-205.

34 Stratton JR, Chandler WL, Schwartz RS, Cerqueira MD, Levy WC, Kahn SE, et al. Effects of physical conditioning on fibrinolytic variables and fibrinogen in young and old healthy adults. Circulation 1991;83:1692-7.

35 Eliasson M, Asplund K, Evrin PE. Regular leisure time physical activity predicts high activity of tissue plasminogen activator: the Northern Sweden MONICA Study. Int $J$ Epidemiol 1996;25:1182-8.

36 El-Sayed MS, Sale C, Jones PG, Chester M. Blood hemostasis in exercise and training Med Sci Sports Exerc 2000;32:918-25.

37 El-Sayed MS, El-Sayed Ali Z, Ahmadizad S. Exercise and training effects on blood haemostasis in health and disease: an update. Sports Med 2004;34:181-200.

38 El-Sayed MS. Effects of high and low intensity aerobic conditioning programs on blood fibrinolysis and lipid profile. Blood Coagul Fibrinolysis 1996;7:484-90.

39 El-Sayed MS. Effects of exercise on blood coagulation, fibrinolysis and platelet aggregation. Sports Med 1996:22:282-98.

40 Centers for Disease Control and Prevention. US physical activity statistics. Department of Health and Human Services, 2007. www.cdc.gov/nccdphp/dnpa/physical/stats/index. $\mathrm{htm}$

Accepted: 28 April 2011 


\section{Tables}

Table 1| Age standardised baseline characteristics (1990) according to physical inactivity, Nurses' Health Study ( $n=69$ 950). Figures are percentages of participants unless stated otherwise

\begin{tabular}{|c|c|c|c|c|c|}
\hline & \multicolumn{5}{|c|}{ Amount of time sitting (2=lowest, $6=$ highest) ${ }^{*}$} \\
\hline & 2 & 3 & 4 & 5 & 6 \\
\hline No of participants & 12451 & 20718 & 24549 & 10403 & 1829 \\
\hline Mean age in 1990 & $56.6(7.2)$ & $56.0(7.1)$ & $56.0(7.1)$ & $56.0(7.0)$ & $59.0(6.9)$ \\
\hline \multicolumn{6}{|l|}{ Amount of time sitting in 1988 (hours/week): } \\
\hline$<10$ & 100 & 36 & 2 & 0 & 0 \\
\hline $11-40$ & 0 & 64 & 81 & 12 & 0 \\
\hline$\geq 41$ & 0 & 0 & 17 & 88 & 100 \\
\hline \multicolumn{6}{|c|}{ Amount of time sitting at home in 1990 (hours/week): } \\
\hline$<10$ & 100 & 64 & 17 & 0 & 0 \\
\hline $11-40$ & 0 & 36 & 81 & 88 & 0 \\
\hline$\geq 41$ & 0 & 0 & 2 & 12 & 100 \\
\hline White race/ethnicity & 96 & 98 & 98 & 99 & 98 \\
\hline \multicolumn{6}{|l|}{ Smoking: } \\
\hline Non-smokers & 45 & 45 & 46 & 43 & 42 \\
\hline Ex-smokers & 37 & 39 & 40 & 42 & 41 \\
\hline Current smokers & 18 & 16 & 14 & 15 & 17 \\
\hline Missing & 0.3 & 0.2 & 0.1 & 0.2 & 0.1 \\
\hline Pack years among ever smokers $† \ddagger$ & 23 & 22 & 23 & 24 & 30 \\
\hline \multicolumn{6}{|l|}{ Spouse's educational attainment: } \\
\hline High school & 36 & 36 & 38 & 37 & 41 \\
\hline College & 23 & 24 & 24 & 24 & 23 \\
\hline Graduate school & 18 & 20 & 20 & 21 & 21 \\
\hline Missing & 23 & 20 & 18 & 18 & 15 \\
\hline Body mass index (BMI) & 25.3 & 25.5 & 25.6 & 26.3 & 27.3 \\
\hline $\begin{array}{l}\text { Total physical activity (metabolic } \\
\text { equivalents/week) } § \S\end{array}$ & 19.6 & 19.7 & 19.7 & 17.8 & 15.7 \\
\hline Total caloric intake (kilocalories/day) $\dagger$ & 1682 & 1722 & 1783 & 1803 & 1840 \\
\hline \multicolumn{6}{|l|}{ Parity: } \\
\hline Nulliparous & 5 & 5 & 6 & 6 & 7 \\
\hline 1 & 7 & 7 & 7 & 7 & 8 \\
\hline $2-3$ & 55 & 55 & 56 & 57 & 52 \\
\hline$\geq 4$ & 31 & 32 & 30 & 29 & 32 \\
\hline Missing & 2 & 1 & 1 & 1 & 1 \\
\hline Premenopausal & 21 & 23 & 23 & 23 & 12 \\
\hline \multicolumn{6}{|c|}{ Hormone replacement therapy after menopause: } \\
\hline None & 27 & 26 & 26 & 27 & 32 \\
\hline Past user & 16 & 15 & 15 & 14 & 20 \\
\hline $\begin{array}{l}\text { Current user of oestrogen replacement } \\
\text { therapy }\end{array}$ & 13 & 13 & 13 & 13 & 14 \\
\hline $\begin{array}{l}\text { Current user of oestrogen-progesterone } \\
\text { replacement therapy }\end{array}$ & 9 & 9 & 10 & 10 & 9 \\
\hline Missing & 14 & 14 & 13 & 13 & 13 \\
\hline Use of NSAIDs & 43 & 45 & 44 & 44 & 42 \\
\hline Warfarin use & 0.9 & 0.8 & 0.9 & 0.9 & 2 \\
\hline Multivitamin supplement use & 37 & 38 & 38 & 39 & 39 \\
\hline Hypertension & 18 & 18 & 18 & 20 & 25 \\
\hline
\end{tabular}




\section{Table 1 (continued)}

\begin{tabular}{|c|c|c|c|c|c|}
\hline & \multicolumn{5}{|c|}{ Amount of time sitting (2=lowest, $6=$ highest $)^{*}$} \\
\hline & 2 & 3 & 4 & 5 & 6 \\
\hline Coronary heart disease $\mathbb{f}$ & 1 & 3 & 3 & 3 & 5 \\
\hline Rheumatological disease ${ }^{\star *}$ & 3 & 3 & 3 & 3 & 4 \\
\hline \multicolumn{6}{|l|}{ Dietary intake (servings/day)†: } \\
\hline Fruits & 1.7 & 1.7 & 1.7 & 1.6 & 1.5 \\
\hline Vegetables & 3.5 & 3.5 & 3.4 & 3.4 & 3.3 \\
\hline Fish & 0.36 & 0.36 & 0.35 & 0.34 & 0.32 \\
\hline Whole grain cereals & 1.3 & 1.3 & 1.4 & 1.4 & 1.4 \\
\hline Refined grain cereals & 1.1 & 1.2 & 1.2 & 1.3 & 1.4 \\
\hline Cured meat & 0.19 & 0.21 & 0.22 & 0.24 & 0.28 \\
\hline Dessert & 0.9 & 1.0 & 1.1 & 1.1 & 1.2 \\
\hline Chips (French fries) & 0.04 & 0.04 & 0.05 & 0.05 & 0.06 \\
\hline
\end{tabular}

NSAIDs=non-steroidal anti-inflammatory drugs.

*Data describing amount of time sitting available from 1988 and 1990 questionnaires. See text for details describing categories of physical activity.

†Age adjusted mean (all such values).

$\ddagger$ No of packs smoked/day $\times$ No of years smoked, among past and current smokers.

§Metabolic equivalent hours/week, sum of average time/week spent in each activity $\times$ metabolic equivalent value of each activity.

ๆCoronary heart disease includes any history of myocardial infarction, coronary artery stenosis, or angina.

${ }^{* *}$ Includes any history of systemic lupus erythematosis or rheumatoid arthritis. 
Table 2| Association between physical inactivity and incident idiopathic pulmonary embolism, Nurses' Health Study ( $\mathrm{n}=69$ 950), with hazard ratios (HR) for trend

\begin{tabular}{|c|c|c|c|c|c|c|}
\hline & \multicolumn{5}{|c|}{ Amount of time sitting (score 2=lowest, 6=highest), combined data from 1988 and 1990} & \multirow{2}{*}{$\begin{array}{l}\text { HR }(95 \% \mathrm{Cl}) \text { for } \\
\text { trend, } \mathrm{P} \text { value }\end{array}$} \\
\hline & 2 & 3 & 4 & 5 & 6 & \\
\hline $\begin{array}{l}\text { No of cases/person } \\
\text { years }\end{array}$ & $41 / 104720$ & $53 / 175518$ & 104/209 002 & $54 / 88228$ & $16 / 14565$ & - \\
\hline $\begin{array}{l}\text { Age adjusted HR }(95 \% \\
\mathrm{Cl})\end{array}$ & 1.00 & $0.79(0.52$ to 1.19$)$ & $1.31(0.90$ to 1.88$)$ & $1.62(1.08$ to 2.44$)$ & $2.73(1.53$ to 4.88$)$ & $\begin{array}{c}1.29(1.15 \text { to } 1.45), \\
<0.001\end{array}$ \\
\hline $\begin{array}{l}\text { Multivariable HR }(95 \% \\
\mathrm{Cl}) \dagger\end{array}$ & 1.00 & $0.79(0.52$ to 1.19$)$ & $1.29(0.90$ to 1.85$)$ & 1.61 (1.07 to 2.42$)$ & 2.68 (1.50 to 4.79$)$ & $\begin{array}{c}1.29(1.15 \text { to } 1.45), \\
<0.001\end{array}$ \\
\hline $\begin{array}{l}\text { Multivariable HR (95\% } \\
\mathrm{Cl}) \ddagger\end{array}$ & 1.00 & $0.79(0.53$ to 1.19$)$ & $1.29(0.89$ to 1.85$)$ & 1.51 (1.01 to 2.28$)$ & 2.34 (1.30 to 4.20$)$ & $\begin{array}{c}1.25(1.12 \text { to } 1.40), \\
<0.001\end{array}$ \\
\hline
\end{tabular}

*Amount of time sitting available from 1988 questionnaire, and amount of time sitting at home available from 1990 questionnaire.

†Adjusted for age, coronary heart disease, hypertension, menopausal status, multivitamin use, use of non-aspirin non-steroidal anti-inflammatory drugs, parity, race, rheumatological disease, spouse's highest educational attainment, smoking status and pack years of smoking, and warfarin use.

¥Additionally adjusted for BMI, total energy intake, physical activity, and dietary pattern. 
Table 3| Association between physical inactivity and incident pulmonary embolism according to level of physical activity, Nurses' Health Study ( $n=69950$ ), with hazard ratios (HR) and $95 \%$ confidence intervals

Amount of time sitting* (1=lowest, 3=highest), combined data from 1988 and 1990

1

HR $(95 \% \mathrm{Cl})$ for trend, P value

Low level of physical activity (<8.4 metabolic equivalents/week)

\begin{tabular}{|c|c|c|c|c|}
\hline No of cases/person years & $25 / 49105$ & $83 / 169990$ & $41 / 49834$ & - \\
\hline Age adjusted HR $(95 \% \mathrm{Cl})$ & 1.00 & $1.01(0.64$ to 1.58$)$ & 1.69 (1.03 to 2.79$)$ & 1.36 (1.04 to 1.76$) 0.02$ \\
\hline Multivariable HR $(95 \% \mathrm{Cl}) \dagger$ & 1.00 & $0.99(0.64$ to 1.56$)$ & $1.66(1.00$ to 2.68$)$ & $1.34(1.03$ to 1.72$) 0.03$ \\
\hline Multivariable HR $(95 \% \mathrm{Cl}) \ddagger$ & 1.00 & $0.98(0.63$ to 1.55$)$ & 1.57 (0.94 to 2.59$)$ & 1.30 (1.00 to 1.69$) 0.05$ \\
\hline \multicolumn{5}{|c|}{ High level of physical activity ( $\geq 8.4$ metabolic equivalents/week) } \\
\hline No of cases/person years & $13 / 46874$ & $65 / 189802$ & $22 / 46607$ & - \\
\hline Age adjusted HR $(95 \% \mathrm{Cl})$ & 1.00 & 1.25 (0.69 to 2.27$)$ & $1.74(0.88$ to 3.46$)$ & $1.33(0.95$ to 1.87$) 0.09$ \\
\hline Multivariable HR $(95 \% \mathrm{Cl}) \dagger$ & 1.00 & 1.23 (0.67 to 2.23$)$ & $1.60(0.81$ to 3.24$)$ & $1.27(0.90$ to 1.80$) 0.17$ \\
\hline Multivariable HR $(95 \% \mathrm{Cl}) \ddagger$ & 1.00 & 1.20 (0.66 to 2.19$)$ & 1.54 (0.77 to 3.09$)$ & 1.25 (0.89 to 1.76$) 0.20$ \\
\hline
\end{tabular}

*Available overall from 1988 questionnaire and for sitting at home from 1990 questionnaire. See text for details.

†Adjusted for age, coronary heart disease, hypertension, menopausal status, multivitamin use, non-aspirin non-steroidal anti-inflammatory drug use, parity, race, rheumatological disease, spouse's highest educational attainment, smoking status and pack years of smoking, and warfarin use.

‡Additionally adjusted for BMI, total energy intake, physical activity, and dietary pattern. 